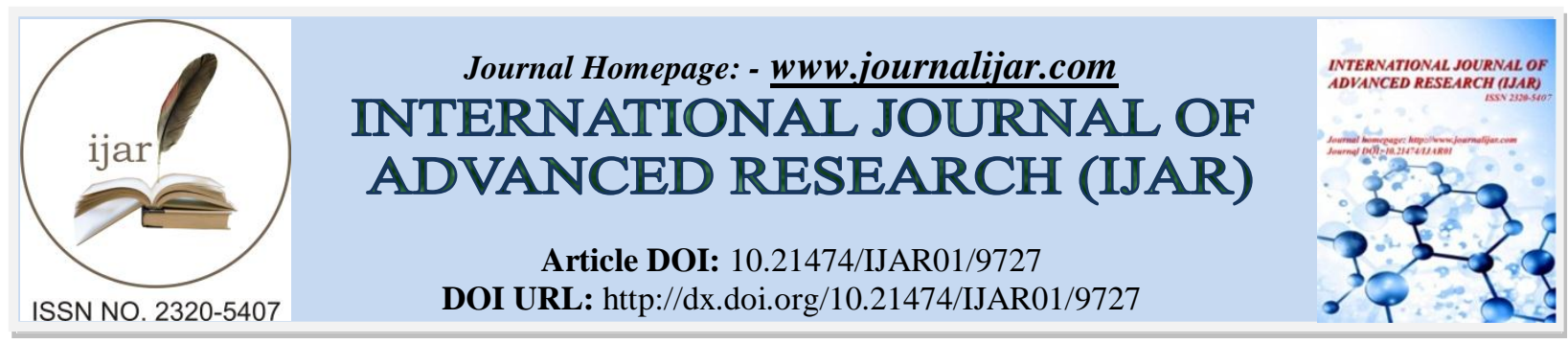

RESEARCH ARTICLE

\title{
ADHERENCE TO ANTIRETROVIRAL THERAPY MEDIATE THE RELATIONSHIP BETWEEN BOTH LIFE AND PSYCHOLOGICAL STRESSES WITH VIRAL LOAD AMONG HIV-POSITIVE PATIENTS.
}

Rami H. Alamoudi.

Department of Industrial Engineering King Abdulaziz University, Jeddah, Saudi Arabia.

\section{Manuscript Info}

Manuscript History

Received: 09 July 2019

Final Accepted: 12 August 2019

Published: September 2019

Key words:-

Life stresses, Psychological Distress,

Treatment Adherence, HIV, Mediator.

\begin{abstract}
Adherence to treatment plays an important role in controlling the HIV disease. However, treatment adherence might be affected by different factors such as stressful life event and psychological distress. Therefore, the goals of this study were to investigate the effects of both of types of stresses on adherence and viral load, and to investigate the association between both stresses - that were being mediated by adherence - with the viral load. In this study, 140 HIV-positive patients participated in the 3-month period study. Stressful life events were measured using Life Events Survey (LES). Psychological stresses were quantified using Kessler Psychological Distress Scale (K10). Both types of stress significantly affected adherence and viral load. Moreover, both stresses and treatment adherence significantly affected viral load. Additional, the association between both types of stresses and viral load was significantly mediated by treatment adherence. Therefore, clear understanding of these mechanisms will aid HIV program managers, growth partners, and researchers in developing strategies to increase adherence awareness.
\end{abstract}

Copy Right, IJAR, 2019,. All rights reserved.

\section{Introduction:-}

Adherence to antiretroviral therapy showed a great effect in minimizing viral load, reduced vulnerability to infections, slow disease progression, which in turns will lead to low cost of combating HIV [1 - 3]. However, adherence to therapy might be affected by psychological distress, such as the fear of HIV progression, drop in health and quality of life, long-term healing, coping with discrimination, and stigma from society. If not properly managed, these psychological distresses may lead to illness, depression, anxiety, substance mistreatment, and quick weakening of health and excellence of life [4 - 6]. A recent study found that high levels of psychological distress symptomatology between HIV-positive individuals following their early diagnosis [7]. Unfortunately, poor adherence to treatment is common [8,9]. A recent investigation initiate that 63 percent of the HIV-positive individuals had missed minimum one dose of their prescribed pills two days before to their visit to the hospital [10]. In Addition, experience of life stressors, such as marital separation, death of a family member, or trouble with employer, worsening financial status, major illness or injury (not HIV related), leads to disease progression via poor healing adherence between HIV-positive individuals. A study found that patients living with HIV who face sensitive tense life events were associated by means of missed pills and schedules at follow-up [11]. Therefore, the goal of this study was to investigate the role of both psychological distress and stressful life events on treatment adherence and viral load among HIV-positive adults, and to investigate if adherence might mediates the relation between both stresses with viral load. Findings from this study would help in developing strategies and/or interventions for

Corresponding Author:-Rami H. Alamoudi.

Address:-Department of Industrial Engineering King Abdulaziz University, Jeddah, Saudi Arabia. 
reducing psychological distress and improving the excellence of life of these victims. Moreover, clear understanding of these mechanisms will aid HIV course managers, development partners, and researchers in developing strategies to increase adherence awareness. In this study, it is hypothesized that both stresses affect adherence and viral load. Additionally, it is hypothesized that adherence to Antiretroviral Therapy moderate the relationship between life stressors, psychological distress levels on the viral load.

\section{Methodology:- \\ Participants}

During this study, 140 qualified participants were HIV-positive patients being treated in Saudi Arabia. All individuals consented to finish the questionnaire of psychological, stressful life events measures taking around 45 minutes to finish. Moreover, a blood test was performed for each participant in order to assay HIV viral load. This investigation was approved by the top board of the university. Table 1 shows the demographic information of the patients who participated in the research.

Table 1:-Demographic Data of the patients participated in the research.

\begin{tabular}{|l|l|l|l|}
\hline Demographic Information & Male & $\%$ & $\mathrm{n}$ \\
\hline \multirow{3}{*}{ Gender } & Female & $47 \%$ & 66 \\
\cline { 2 - 4 } & $<20$ & $53 \%$ & 74 \\
\cline { 2 - 4 } & $20-30$ & $13 \%$ & 18 \\
\cline { 2 - 4 } & $31-40$ & $27 \%$ & 38 \\
\cline { 2 - 4 } & $>40$ & $33 \%$ & 46 \\
\hline \multirow{3}{*}{ Occupation } & Employed & $27 \%$ & 38 \\
\cline { 2 - 4 } & Unemployed & $33 \%$ & 46 \\
\hline \multirow{4}{*}{ Education } & No education & $67 \%$ & 94 \\
\cline { 2 - 4 } & Preliminary & $1 \%$ & 1 \\
\cline { 2 - 4 } & Secondary & $33 \%$ & 46 \\
\cline { 2 - 4 } & Postsecondary & $46 \%$ & 64 \\
\hline
\end{tabular}

\section{Experimental Protocol}

Each participant completed a self-report measure of their daily stress events (i.e. Life Events Survey (LES)) and their level of psychological distress (i.e. Kessler Psychological Distress Scale (K10)) upon entry into the study. Three months later, their level of adherence was assessed by quantifying the proportion of their prescribed medication that they had taken during that 3-month period. Following the adherence assessment, a sample of blood was collected and assayed for viral load.

\section{Statistical Analysis:-}

Since adherence might be affected by psychological stress, and stressful life events, then adherence might mediates the relationship between both of them and viral load. Therefore, a Sobel's mediation test was conducted. Moreover, regression analysis was conducted on the effect of both stresses on adherence. Additionally, the effect of both stresses and adherence on viral load was investigated using a regression analysis. In all models the level of significance of $\alpha=0.05$. Moreover, SPSS software, version 16 was used in the statistical analysis. Figure 1 below shows all the relationships in the analysis.

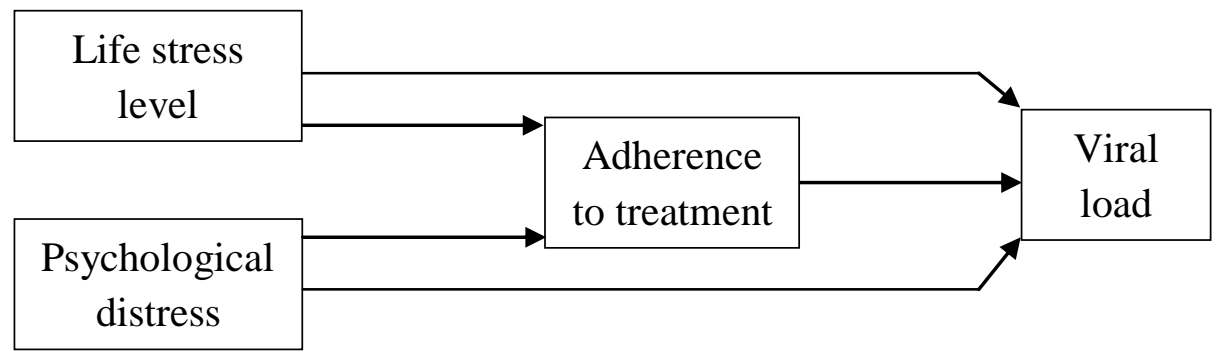

Figure 1:-Relationship between life stressors and psychological stresses the viral load. Treatment adherence mediates the association between both stresses and viral load. 


\section{Measurements \\ Adherence to Antiretroviral Therapy}

The regular examination of patient adherence was implemented during the use of a customized development note that included a line item concerning patient adherence to antiretroviral treatment. On each day, every patient answered a one question that asked if they have taken the pills on that day or not during 3-months period. At the end of the study period, adherence to treatment was measured by quantifying the percentage of their prescribed medication that they had taken during that 3-month period.

\section{Stressful Life Events}

Latest stressful life actions were measured using an updated description of the Life Events Survey (LES) that evaluated the existence of stressful events during 3-month period [12,13]. In a recent study, this measure was shown to compare with poor health in a large sample of immune decline and progression of HIV disease [14 - 17]. For the present analysis, we examined the following stressful events: change in marital status (such as, marriage, divorce), illness or death of family members or friends, work or financial problems (such as, job loss, huge drop in income), illness (non-HIV related), accidents or safety matters (such as, physical or sexual assault), legal or crime issues (such as, relative arrested, burglarized), other life events (such as, pregnancy, change residence more than once). Therefore, the number of stressful events was measured by calculating the percentage of number of stressors.

\section{Psychological Distress}

Using the Kessler Psychological Distress Scale, Psychological Distress was measured (K10) [18]. This can be used as a tiny screen to classify levels of distress. The K10 scale consists of ten questions regarding emotional status each with a 5-level response scale. The device can be given to patients to answer, or on the further hand the questions can be translate to the patient by the practitioner. Every item is ranked from " 1 " 'none of the time' to "5" 'all of the time'. Ranks of the ten items are then added, yielding a smallest rank of ten and a highest score of fifty. High scores specify high levels of psychological distress and low scores specify low levels of psychological distress.

\section{Viral Load}

In order to measure HIV viral load (copies/mL), a blood test is conducted in order to calculate the number (particles or copies) of HIV particles in a milliliter (mL) of blood. This blood test assesses the progression of HIV in the body. It's also useful in seeing how well Antiretroviral Therapy is controlling HIV in the body. A low viral load indicates relatively few copies of HIV in the blood. If the treatment plan is effective, a person will be able to maintain a lower viral load. A high viral load may indicate a recent HIV transmission, or untreated HIV. The amount of viral load decreases as the body's immune system fights against HIV. Because viral loads have a huge range of numbers they are expressed in 'log units' to make it easier to write them on diagram. Moreover, researchers use log scales to look at changes to viral loads over time.

\section{Results:-}

Table 1 shows the descriptive statistics, regression coefficients, and significance value for each variable of both models, i.e. the mediation model, and the entire model. Moreover, Figure 2 below represents the relation between the numbers of stressful life events with the adherence percentage. Clearly, with lower stressful life events, patients to be more adherent to HIV therapy.

Table 2:-Descriptive statistics, regression coefficients, and their test of significance of both models $(\alpha=0.05)$

\begin{tabular}{|l|l|l|l|l|l|}
\hline & \multicolumn{2}{|l}{$\begin{array}{l}\text { Descriptive } \\
\text { Statistics }\end{array}$} & $\begin{array}{l}\text { Effect of Psychological Distress and } \\
\text { Stressful Life Events on Treatment } \\
\text { Adherence }\end{array}$ & $\begin{array}{l}\text { Effect of Psychological Distress, } \\
\text { Stressful Life Events, and Adherence on } \\
\text { Viral Load }\end{array}$ \\
\cline { 2 - 6 } & $\begin{array}{l}\text { Mean } \\
\text { (SD) }\end{array}$ & $\begin{array}{l}\text { Regression } \\
\text { Coefficients }\end{array}$ & Significance & $\begin{array}{l}\text { Regression } \\
\text { Coefficients }\end{array}$ & Significance \\
\hline $\begin{array}{l}\text { Stressful events } \\
\text { measure }\end{array}$ & $\begin{array}{l}0.8449 \\
(0.18896)\end{array}$ & -0.019 & $\mathrm{p}<0.01$ & 0.12 & $\mathrm{p}<0.001$ \\
\hline $\begin{array}{l}\text { Psychological } \\
\text { distress }\end{array}$ & $\begin{array}{l}45.46 \\
(3.756)\end{array}$ & -0.001 & $\mathrm{p}<0.01$ & 0.035 & $\mathrm{p}<0.05$ \\
\hline Adherence (\%) & $\begin{array}{l}0.8875 \\
(0.2487)\end{array}$ & - & - & -7.516 & $\mathrm{p}<0.001$ \\
\hline Viral Load & 3.911 & - & - & - & - \\
\hline
\end{tabular}




\begin{tabular}{|l|l|l|l|l|l|}
\hline (copies/mL) & $(3.945)$ & & & & \\
\hline
\end{tabular}

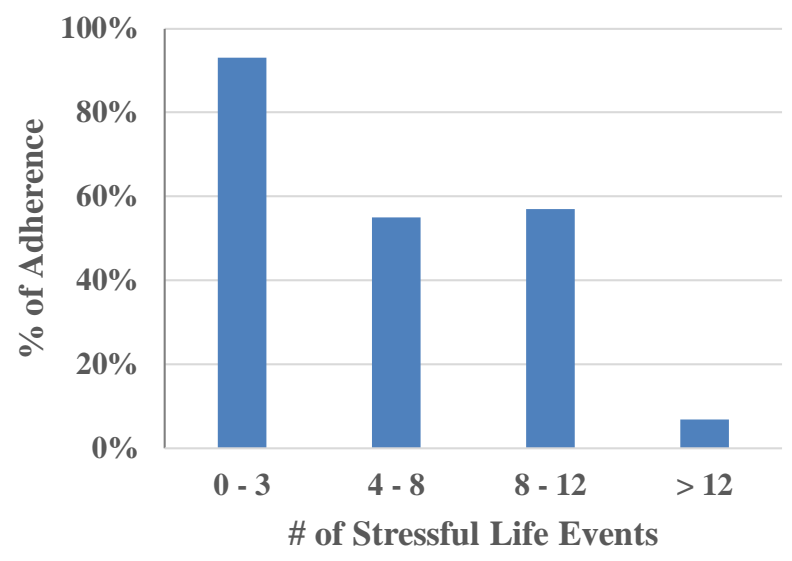

Figure 2:-The association between the number of stressful events, and the adherence to treatment.

\section{Effect of Stressful Life Events and Psychological Distress on Treatment Adherence}

Both types of stresses were statistically significant ( $\mathrm{p}$-value $<0.01$ ). When the stress level and psychological distress equal to zero, the mean adherence of the population will be equaled to 1.036. Moreover, for every unit change in the amount of the daily stress level, adherence to treatment percentage will decrease by 0.019 , controlling the level of psychological distress. Also, for every unit change in the level of psychological distress, treatment adherence will decrease by 0.001 , controlling the amount of the daily stress level, as shown in the equation (1).

Adherence $=1.036-0.019$ stress level -0.001 psychological distress

\section{Effect of Psychological Distress, Stressful Life Events, and Adherence on Viral Load}

Psychological distress, Stressful life events, and treatment adherence significantly affect the amount of HIV viral load. For every unit change in the amount of the daily stress level, viral load will increase by 0.012 , controlling the level of psychological distress and the adherence. Also, for every unit change in the level of psychological distress, viral load will increase by 0.035 , controlling the amount of the daily stress level and the adherence. Also, for every unit change in the adherence, viral load will decrease by 7.516, controlling the amount of the daily stress level and the level of psychological distress, as show in the equation (2).

Viral Load $=11.146+0.012$ stress level +0.035 psychological distress -7.516 adherence

\section{Test of Mediation Hypothesis}

In this study, it was hypothesized that treatment adherence might mediates the relationship between both life stress and psychological stress with viral load. In mediation, the relationship between the both stresses and the viral load is an indirect relation that exists due to the influence of the adherence to treatment. As a result, when the adherence to treatment is included in a regression analysis model with the both stresses, their effects is reduced and the effect of the adherence remains significant. In order to test for mediator significance, Sobel's test is used. The mediator (i.e. adherence) level of significance p-value was $<0.001$. Therefore, adherence to treatment mediates the relationship between stressful events of life and viral load.

\section{Discussion:-}

Preceding studies have shown that HIV-positive individuals have difficulties in adhering to healing, which certainly affect the progression of the disease. The current study was designed to examine the effect of psychological distress and stressful life events on viral load. Moreover, another goal was to investigate the potential mediator role of adherence to treatment between both types of stresses and viral load. Patients who reported high stressful life events may have more difficult lifestyles that may affect them to miss their medications. A recent study found that those with stressful life events and low tolerance were prone to missing their medications [19]. These results suggest that interventions for depressed patients is important, but mental behavioral interventions that focus on stress management and reducing it might improve adherence to HIV treatment [20]. It appears that life stressors guide 
individuals to high levels of depression that force the patients to be at a high risk for failing to adhere to healing and consequent declines in health.

The results of current study showed that psychological distress significantly affect adherence. A greater part of the respondents in this research were mentally and socially unwell. In excess of half $(71.5 \%)$ of them reported being concerned, depressed, or overwhelmed. This findings were in line with other studies that showed that anxiety and depression were noted to be the psychological factors related with nonadherence [21, 22]. These feelings were expected as the patients may be subjected to psychological challenges at home, in school, or from the community. Proposals mental stressors took a few structures including trashing, separation, shirking, inconsistent treatment contrasted and individuals. All these emotional issues significantly affected the level of adherence in a negative way. Adherence is considered the only most important dispute to successful control of HIV- infected individuals [23, 24]. Adherence to treatment might be improved by caregivers, medications, disease, or removing psychological barriers; with the psychological factors being more related to nonadherence [25]. This was clear in this research as perception of having a unfortunate state of health, depression, anxiety, and discrimination contributed to poor adherence. Recent study found that the level of adherence in the developing countries is similar or higher than the developed countries, despite fears and concerns [26]. The level of adherence observed in this study was high and similar to other recent studies in the developing countries of more than 75 percent (vary: 45-100 perecent) [27]. On the other hand, level of adherence in developed countries were lower, with majority below 75 percent (range: $20-100$ percent) $[28,29]$.

In this study, the relationship between the both stresses and the viral load was an indirect relation that exists due to the influence of the adherence to treatment. As a result, when the adherence to treatment is included in a regression analysis model with the both stresses, their effects is reduced and the effect of the adherence remains significant.

\section{Conclusion:-}

It was concluded that both stresses had significant effects of adherence and viral load. Moreover, adherence significantly affect viral load. Moreover, adherence mediates significantly the relation between both stresses and viral load. Clear understanding this mediation will aid HIV program managers, growth partners, and researchers in increasing in developing strategies to increase adherence awareness. HIV-infected individuals have different and aware needs that require high attention of program managers and the society to achieve the required level of adherence to treatment. Future studies should consider studying and exploring how to manage psychological challenges as important as focusing on the infected individuals. There are some important aspects that should be included in the routine management of HIV, such as training of caregivers professionals, establishment of mechanisms, health-care professionals education, record, and the use of multidisciplinary healing teams, such as case supervisors, doctors, nurses, and psychiatrists. Health-care professionals can play an important role if they are well prepared. A family- oriented support program was exposed to be successful and minimize psychological stresses such as, discrimination, stigma, and depression, and in turn improve adherence [24]. This program should be adapted and maintained in all healthcare centers that deal with similar challenges. Finally, it is worthwhile to note the limitations of the study. First, the sample size of this study was relatively low, which might lower the power and the strength of the statistical tests. The reason behind that was it was not easy to approach a large sample of HIV patients. Also, many of the patients left the study without completing the data.

\section{References:-}

1. Remmert JE, et al. Psychosocial syndemics are additively associated with worse ART adherence in HIVinfected individuals. AIDS Behav. 2015;19:981-6. 8.

2. Brown JL, Littlewood RA, Vanable PA. Social-cognitive correlates of antiretroviral therapy adherence among HIV-infected individuals receiving infectious disease care in a medium-sized northeastern US city. AIDS Care 2013;25(9):1149-58. 9.

3. Malow R, Dévieux JG, Stein JA, Rosenberg R, Jean-Gilles M, Attonito J, et al. Depression, substance abuse and other contextual predictors of adherence to antiretroviral therapy (ART) among Haitians. AIDS Behav 2013;17(4):1221-30.

4. WHO. Adolescent HIV Testing, Counselling and Care: Implementation Guidance for Health Providers and Planners. Available at: http://apps.who.int/adolescent/hiv-testing-treatment/page/Psychosocial_well_being (last accessed on October 20, 2018) 5. 
5. Remien RR, Rabkin JG. Psychological aspects of living with HIV disease: A primary care perspective. West J Med 2001;175(5):332-5.

6. Vranda MN, Mothi SN. Psychosocial issues of children infected with HIV/AIDS. Indian J Psychol Med 2013;35(1):19-22.

7. Katz S, Nevid JS. Risk factors associated with posttraumatic stress disorder symptomatology in HIV-infected women. AIDS Patient Care STDs 2005;19:110-120.

8. Carmona A, Knobel H, Guelar A, et al. Factors influencing survival in HIV infected patients treated with HAART. Presented at 13th International AIDS Conference. Durban, South Africa, July 9-14, 2000.

9. Walsh JC, Hertogs K, Gazzard B. Viral drug adherence and pharmacokinetic indices in HIV-1 infected patients on successful and failing protease inhibitor (PI) based highly active antiretroviral therapy (HAART). Presented at the 40th Interscience Conference of Antimicrobial Agents and Chemotherapy. Toronto, Canada, September $17-20,2000$.

10. Hewitt R, Roberts JE, Shelton MJ, Esch LD. Psychological factors and future adherence to antiretroviral therapy. Poster presented at the 1st International AIDS Society Conference on HIV Pathogenesis and Treatment. Buenos Aires, Argentina, July 8-11, 2000.

11. Nevid JS. Risk factors associated with posttraumatic stress disorder symptomatology in HIV-infected women. AIDS Patient Care STDs 2005;19:110-120.

12. Sarason IG, Johnson JH, Siegel JM. Assessing the impact of life changes: Development of the Life Experiences Survey. J Consult Clin Psychol 1978;46:932-946.

13. Sarason IG, Johnson JH. The Life Experiences Survey: Preliminary findings. Technical Report SCS-LS-001. Office of Naval Research, 1976

14. Leserman J, Whetten K, Lowe K, Stangl D, Swartz MS, Thielman NM. How trauma, recent stressful events, and PTSD affect functional health status and health utilization in HIV-infected patients in the south. Psychosom Med 2005;67:500-507.

15. Leserman J, Jackson ED, Petitto JM, et al. Progression to AIDS: The effects of stress, depressive symptoms, and social support. Psychosom Med 1999;61:397-406.

16. Leserman J, Petitto JM, Gu H, et al. Progression to AIDS, a clinical AIDS condition, and mortality: Psychosocial and physiological predictors. Psychol Med 2002;32:1059-1073.

17. Leserman J, Petitto JM, Perkins DO, Folds JD, Golden RN, Evans DL. Severe stress, depressive symptoms, and changes in lymphocyte subsets in human immunodeficiency virus-Inf

18. Kessler RC, Barker PR, Colpe LJ, Epstein JF, Gfroerer JC, Hiripi E, et al. Screening for serious mental illness in the general population. Arch Gen Psychiatry. 2003 Feb;60(2):184-9.

19. O'Cleirigh C, Ironson G, Smits JA. Does distress tolerance moderate the impact of major life events on psychosocial variables and behaviors important in the management of HIV? Behav Ther 2007;38:314-323.

20. Simoni JM, Pearson CR, Pantalone DW, Marks G, Crepaz N. Efficacy of interventions in improving highly active antiretroviral therapy adherence and HIV-1 RNA viral load. A meta-analytic review of randomized controlled trials. J Acquir Immune Defic Syndr 2006;43(Suppl 1):S23-S35.

21. Lwanga SK, Lemeshow S. Sample Size Determination in Health Studies, a Practical Manual. Geneva: World Health Organization, 1991. pp. 1-3. Available at: http://apps.who.int/ iris/ handle/10665/40062 (last accessed on November 11, 2018).

22. Reisner SL, Mimiaga MJ, Skeer M, Perkovich B, Johnson CV, Safren SA. A review of HIV antiretroviral adherence and intervention studies among HIV-infected youth. Top HIV Med 2009;17(1):14-25.

23. Agwu AL, Fairlie L. Antiretroviral treatment, management challenges and outcomes in perinatally HIVinfected adolescents. J Int AIDS Soc 2013;16:18579.

24. Mavhu W, Berwick J, Chirawu P, Makamba M, Copas A, Dirawo J, et al. Enhancing psychosocial support for HIV positive adolescents in Harare, Zimbabwe. PLoS ONE 2013;8(7):e70254.

25. Reda AA, Biadgilign S. Determinants of adherence to antiretroviral therapy among HIV-infected patients in Africa. AIDS Res Treat 2012;2012:574656. Available at: http://dx.doi. org/10.1155/2012/574656 (last accessed on September 26, 2018).

26. Kathryn A. Bottonari, John E. Roberts, Jeffrey A. Ciesla, And Ross G. Hewitt, Life Stress and Adherence to Antiretroviral Therapy among HIV-Positive Individuals: A Preliminary Investigation. AIDS PATIENT CARE and STDs. Volume 19: 717- 727.

27. Vreeman RC, Wiehe SE, Pearce EC, Nyandiko WM. A systematic review of pediatric adherence to antiretroviral therapy in low- and middle-income countries, Pediatr Infect Dis J 2008;27(8):686-91.

28. Mills EJ, Nachega JB, Buchan I, Orbinski J, Attaran A, Singh S, et al. Adherence to antiretroviral therapy in sub-Saharan Africa and North America: A meta-analysis. JAMA 2006;296(6):679-90. 
29. Simoni JM, Montgomery A, Martin EM, New M, Demas PA, Rana S. Adherence to antiretroviral therapy for pediatric HIV infection: A qualitative systematic review with recommendations for research and clinical management. Pediatrics 2007;119(6):1371-83. 